\title{
Mapping Out Biogenetic Hypotheses by Chemical Synthesis
}

\author{
Raphael Liffert and Karl Gademann*
}

\begin{abstract}
Synthesis of natural products via their postulated or established biosynthetic intermediates ("biomimetic synthesis' or 'bio-inspired synthesis') has the power to identify both yet undiscovered intermediates and undiscovered mechanistic pathways for their formation. In this account, we report on our recent studies on unusual hypotheses for biosynthetic transformations, such as a late-stage aldol reaction (periconianone A), benzilic acid rearrangement (taiwaniaquinone $\mathrm{H}$ ), a redox-neutral light-driven $\mathrm{C}-\mathrm{H}$ activation (taiwaniaquinol $\mathrm{A}$ and cyclocoulterone), a hetero Diels-Alder reaction (obtusinones), aziridinium chemistry (Securinega alkaloids), and a [3+2] nitrone olefin cycloaddition (virosaine A). All these studies provided evidence on the molecular level for the feasibility of these transformations, and suggest that further studies investigating the relevance of these hypotheses in biological systems are warranted.
\end{abstract}

Keywords: Biomimetic chemistry · Biosynthesis $\cdot$ Natural products · Organic synthesis

\section{Introduction}

The structural complexity of natural products has fascinated chemists for centuries and has challenged them to rationalize the biogenesis of these substances. In 1835, Wöhler wrote: "Die organische Chemie kann einen jetzt ganz toll machen. Sie kommt mir wie ein Urwald der Tropenländer vor, voll der merkwürdigsten Dinge, ein ungeheures Dickicht, ohne Ausgang und Ende, in das man sich nicht hinein wagen mag."[1] In the following decades, scientists started to map out this thicket, first by advances in structure elucidation, by chemical synthesis and correlation, and then by advancement in analytical instrumentation. ${ }^{[2]}$ In the context of these synthetic endeavors, many synthetic
${ }^{*}$ Correspondence: Prof. Dr. K. Gademann Department of Chemistry University of Zurich

Winterthurerstrasse 190, CH-8057 Zurich

E-mail: karl.gademann@uzh.ch relationships between postulated or actual biogenetic intermediates were uncovered, that then led to the formulation of biosynthetic pathways for their production in the natural system. ${ }^{[3]}$ Efforts by hundreds and thousands of scientists led to the elucidation of metabolic pathways culminating in the landscape that is taught to undergraduate students in science and medicine today. However, one might ask the question if there are still unmapped territories in Wöhler's primordial jungle and if there are new biosynthetic routes to be discovered. In this highlight, we would like to present unusual and rarely investigated mechanistic hypotheses related to the biogenesis of natural products. The feasibility of these pathways has been validated by chemical synthesis. While it is interesting to speculate about mechanistic ramifications in biochemistry, this work presents a suggestion to further investigate the presence of such routes in nature. In addition, this account is limited to examples from our own research group, which are obviously selective and biased, and are by no means comprehensive.

\section{Biogenetic Proposals Investigated by Chemical Synthesis}

Periconianone A (1) was recently isolated from the endophytic fungus Periconia sp. F-31, which is found in the medicinal plant Annona muricata. ${ }^{[4]}$ The eremophilane-type sesquiterpenoid features an architecturally complex, rigid, and highly oxidized molecular structure with a unique 6/6/6 tricarbocyclic framework and five contiguous stereocenters. The final ring closure to complete the cage-like skeleton is biogenetically proposed to be the result of a late-stage aldol addition in 2. ${ }^{4}$ The bicycle 2 itself is proposed to be derived from eremophilane (3) through several oxidative transformations. ${ }^{[4]}$ Inspired by the proposed biosynthetic pathway, we envisaged to mimic this late-stage aldol reaction in order to establish the stereogenic centers at $\mathrm{C} 4$ and $\mathrm{C} 12$ and to form the strained framework from the highly oxidized precursor 4 . The main synthetic challenges of this transformation are the construction of a motif with two contiguous all-carbon quaternary stereocenters

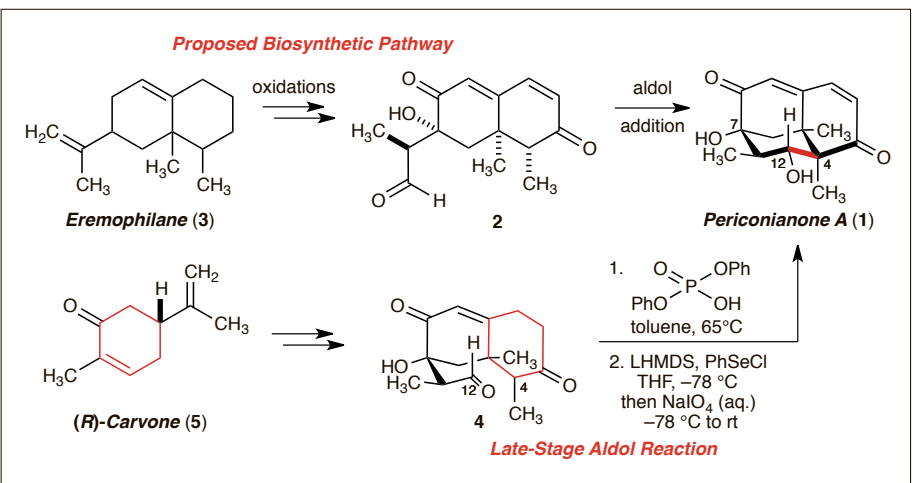

Scheme 1. Proposed biosynthetic pathway and synthetic strategy to periconianone A (1). 
(C4 and C5), high ring strain in the formation of the cage-like framework, as well as the intermediacy of labile $\beta$-hydroxy ketone $\mathbf{4}$, prone to elimination and retro-aldol reactions.

In order to probe the biogenetic key transformation, an efficient and enantioselective synthetic route starting from commercially available $(R)$-carvone (5) was developed and gave access to isomerically pure aldehyde $\mathbf{4}$ in 15 linear steps. Distinctive features of this route are the use of an isopropenyl group as a removable directing group for stereoselective synthesis, a Rh-mediated tandem $\mathrm{O}-\mathrm{H}$ insertion/[3,3]-sigmatropic rearrangement and subsequent $\alpha$-ketol rearrangement. Using various basic and acidic conditions for the key transformation only induced a retro-aldol reaction by cleavage of propanal from 4 to form the undesired diosphenol. After extensive screening, organic phosphonic acids were shown to mediate the desired substrate-controlled aldol cyclization in a regio- and diastereoselective manner, and without significant side product formation, even in the presence of the free tertiary alcohol at C7. Treatment of aldehyde 4 with diphenyl phosphate in toluene at $65{ }^{\circ} \mathrm{C}$ gave the tricycle in $71 \%$ yield and full diastereoselectivity and final oxidation gave access to periconianone A (1, Scheme 1). ${ }^{[5]}$

The taiwaniaquinoids are a family of diterpenoids possessing an unusual 6/5/6 carbocyclic system containing a benzylic quaternary stereogenic center. They often feature a $\mathrm{CHO}$ group at different positions $\left(\mathrm{C}_{20}\right.$ taiwaniaquinoids) or are devoid of a $\mathrm{C}$ atom $\left(\mathrm{C}_{19}\right.$ taiwaniaquinoids $)$ representing norditerpenoids. ${ }^{[6]}$ Our biogenetic hypothesis towards $\mathrm{C}_{19}$ taiwaniaquinoids is based on a B-ring contraction of the abietane-type $6 / 6 / 6$ tricyclic systems, to form the corresponding taiwaniaquinoid $6 / 5 / 6$ system and is supported by reports on the biosynthesis of gibberellins. ${ }^{[7]}$ In the total synthesis of taiwaniaquinone $\mathrm{H}(\mathbf{6}),{ }^{[8]}$ treatment of oxidized ferruginol (7, synthesized from abietic acid (8)) with LHMDS has been shown to trigger a rearrangement to the ketone 9. The mechanism of this reaction is proposed to be internal nucleophilic attack of the deprotonated hydroxy group, resulting in the 3-oxetanone intermediate 10. The biosynthetic intermediacy of $\mathbf{1 0}$ is further supported by the occurrence of more than 20 steroid derivatives containing 3-oxetanone moieties in their B-ring. ${ }^{[9]}$ Oxetanone $\mathbf{1 0}$ is then proposed to undergo the key benzilic acid rearrangement to form lactone intermediate 11, followed by decarboxylation to the norditerpenoid framework 9. Ketone 9 was converted to taiwaniaquinone $\mathrm{H}$ in a six-step protocol and the total synthesis has been achieved without the use of a protecting group (Scheme 2).
Other members of the taiwaniaquinoids family which have aroused our synthetic interest are taiwaniaquinone $F(\mathbf{1 2})$, as well as its rearranged methylene-bridged catechol taiwaniaquinol A (13). The total synthesis of taiwaniaquinone $\mathrm{F}$ has been achieved via a protecting-group-free route starting from sugiol methyl ether (14, prepared form commercially available abietic acid (8)) in nine steps. ${ }^{[10]}$ The B-ring contraction to the $6 / 5 / 6$ skeleton has been accomplished in a Wolff rearrangement by irradiating the $\alpha$-diazoketone derived from 14 with a medium pressure $\mathrm{Hg}$ lamp. When taiwaniaquinone $\mathrm{F}$ (12) was exposed to light during purification, formation of taiwaniaquinol A (13) was observed, and by exposure of a diluted solution of $\mathbf{1 2}$ to sunlight, we were able to perform this transformation to $\mathbf{1 3}$ with $30 \%$ isolated yield (Scheme 3). For several natural products, studies describe the involvement of cytochrome P450 enzymes in the oxidative cyclization to the benzo[1,3]dioxole units. ${ }^{[11]}$ However, in the context of our biomimetic synthesis to taiwaniaquinol A, we were able to mimic this transformation as a redox-neutral, light-mediated and enzyme-free remote $\mathrm{C}-\mathrm{H}$ activation process. The occurrence and distribution of taiwaniaquinone $\mathrm{F}$ and taiwaniaquinol $\mathrm{A}$ in the plant Taiwania crytomerioides further supports our biosynthetic hypothesis by a light-mediated process, since the former was isolated from the bark and the latter from the leaves of the same plant.[12]
In a collective synthesis of icetexane natural products, we investigated the B-ring expansion of abietane diterpenoids to the $6 / 7 / 6$ tricyclic framework and have delivered evidence that the 6/6/6 abietane skeleton could be a biosynthetic precursor of the icetexanes. ${ }^{[13]}$ Mechanistically, the transformation of $\mathbf{1 5}$ (via carnosic acid obtained from rosemary) to $\mathbf{1 6}$ and $\mathbf{1 7}$ is explained by formation of a primary carbocation at C20 in the 6/6/6 skeleton $\mathbf{1 5}$, which immediately undergoes ring-expansion via a $[1,2]$-shift of the C9-C10 bond to form the more stable tertiary carbocation $\mathbf{1 8}$ (Scheme 4). Results published earlier have already described experimental evidence for the formation of alkenes $\mathbf{1 6}$ by deprotonation of 18. ${ }^{[14]}$ However, trapping of $\mathbf{1 8}$ by water to install the oxygen function at the $\mathrm{C} 10$ position to form the icetexanes has not been reported previous to this work and had been debated in the literature for decades. ${ }^{[15]}$ Attack of water from the $\beta$ face to form the desired icetexanes had been considered to be sterically disfavored. ${ }^{[15 \mathrm{c}]}$ However, the exclusively observed $\beta$ selectivity in our approach supports a nonenzymatic mechanism for this transformation. Following our biomimetic route, we were able to access the natural products salvicanol (19), komaroviquinone (20), cyclocoulterone (21), and komarovispirone (22), starting from carnosic acid, which was obtained as dimethoxycarnosate methyl ester from rosemary upon derivatization (Scheme 4). Additionally, we applied the

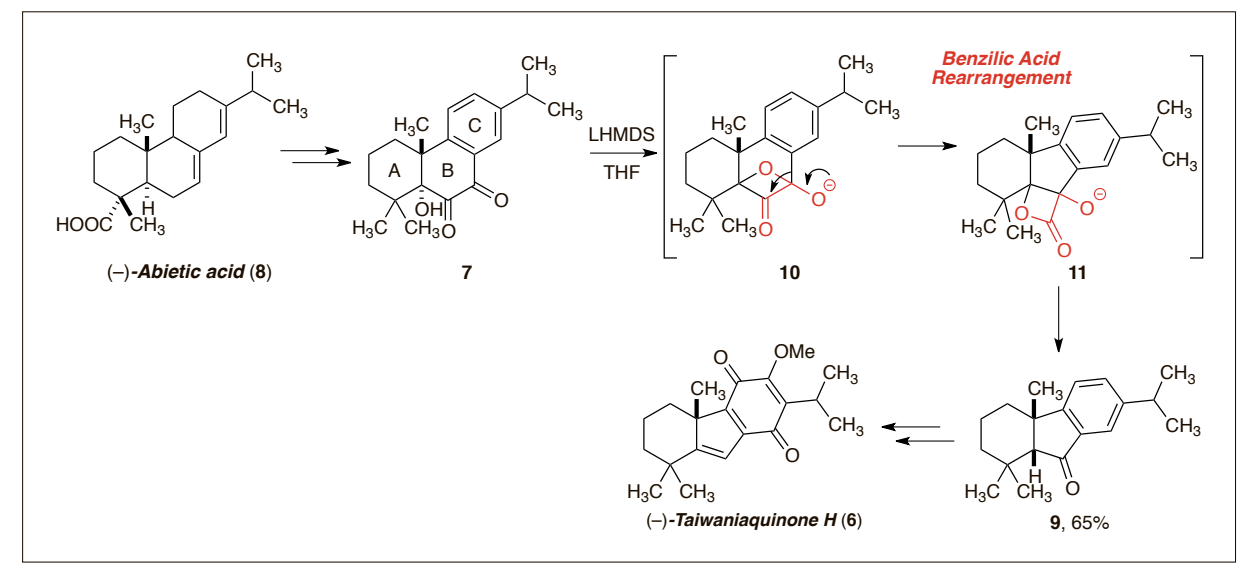

Scheme 2. Biomimetic total synthesis of taiwaniaquinone $\mathrm{H}(6)$ via a benzilic acid rearrangement.

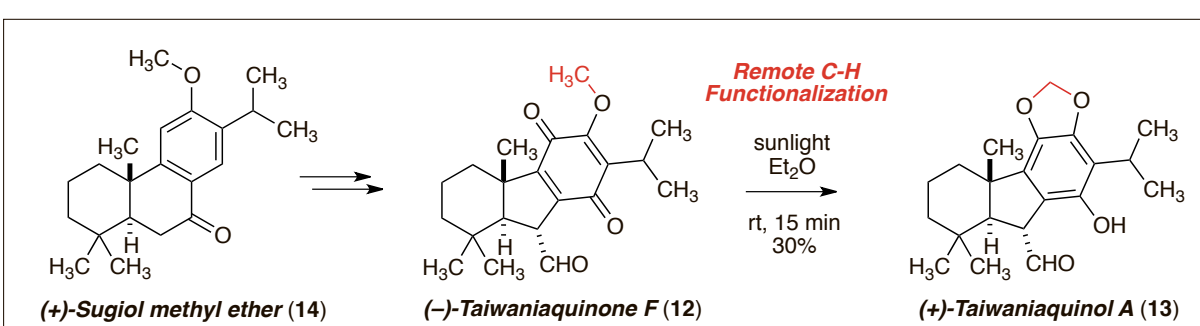

Scheme 3. Total synthesis of taiwaniaquinone $\mathrm{F}(\mathbf{1 2})$ and its biomimetic remote $\mathrm{C}-\mathrm{H}$ functionalization to taiwaniaquinol $\mathrm{A}(\mathbf{1 3})$. 
light-promoted remote $\mathrm{C}-\mathrm{H}$ activation in the reaction of $\mathbf{2 0}$ to $\mathbf{2 1}$ and $\mathbf{2 2}$, and provided additional experimental evidence for the feasibility of this transformation.

Complex dimeric diterpenoids have been rarely isolated and the structural complexity obtained by dimerization is remarkable. For the icetexane class, grandione has already been synthesized, ${ }^{[16,17]}$ whereas obtusinones D and E were isolated from Premna obtusifolia and postulated to be the result of a [4+2] cycloaddition reaction. ${ }^{[18]}$ Evaluating this hypothesis, we prepared the quinone $\mathbf{2 3}$, which we demonstrated to be not identical to the structure of przewalskin E. ${ }^{[13]}$ Heating neat quinone 23 at $100{ }^{\circ} \mathrm{C}$ for six hours led to the formation of both obtusinone $\mathrm{D}$ and $\mathrm{E}$ in $69 \%$ yield and in a 1.7:1 ratio. Separation of the natural products by chromatography proved to be difficult, and the trick was to use additional toluene to break down stacking for subsequent separation. The NMR spectra matched to the reported data, but X-ray crystal structure analysis established that configurations at $\mathrm{C} 13$ and C14 were opposite. ${ }^{[13]}$ Based on this evidence, we proposed a structural revision of both compounds to the structures shown in Scheme 5.

Securinega alkaloids constitute an interesting class of alkaloids that display highly functionalized complex structures reaching out to oligomeric congeners. ${ }^{[19]}$ Their biogenesis has been suggested to start from lysine and tyrosine, with $\mathbf{2 6}$ as an intermediate. Hypotheses for the biogenesis of Securinega alkaloids featuring a bicyclo [3.2.1] skeleton (e.g. allosecurinine (27)) or a bicyclo [2.2.2] skeleton (e.g. secu' amamine E (28)) emanating from this central precursor have been formulated. In contrast, a linear hypothesis in which secu'amamine $\mathrm{E}$ is a biosynthetic intermediate en route to the [3.2.1] congener can be formulated. By using chemical synthesis, we prepared both secu'amamine E and the nor-congener, bubbialidine (29). [20] Interestingly, both compounds readily convert to the rearranged products allosecurinine (30) or (-)-allonorsecurinine (31), respectively. In the case of bubbialine (32), which displays a synperiplanar arrangement of the aminoalcohol unit, such a rearrangement is not directly possible, and the mesylate intermediate $\mathbf{3 3}$ was observed. Forcing conditions converted this intermediate to the product allonorsecurinine (34, Scheme 6). Based on this evidence, it is suggested that an aziridinium intermediate 35 might be involved in this transformation, and its ease of formation via suitable arrangement of the non-bonding orbital of the $\mathrm{N}$ atom into the $\sigma^{*}$ orbital of the C-OMs bond.

The complex alkaloid virosaine A (36) was isolated from the twigs and leaves of

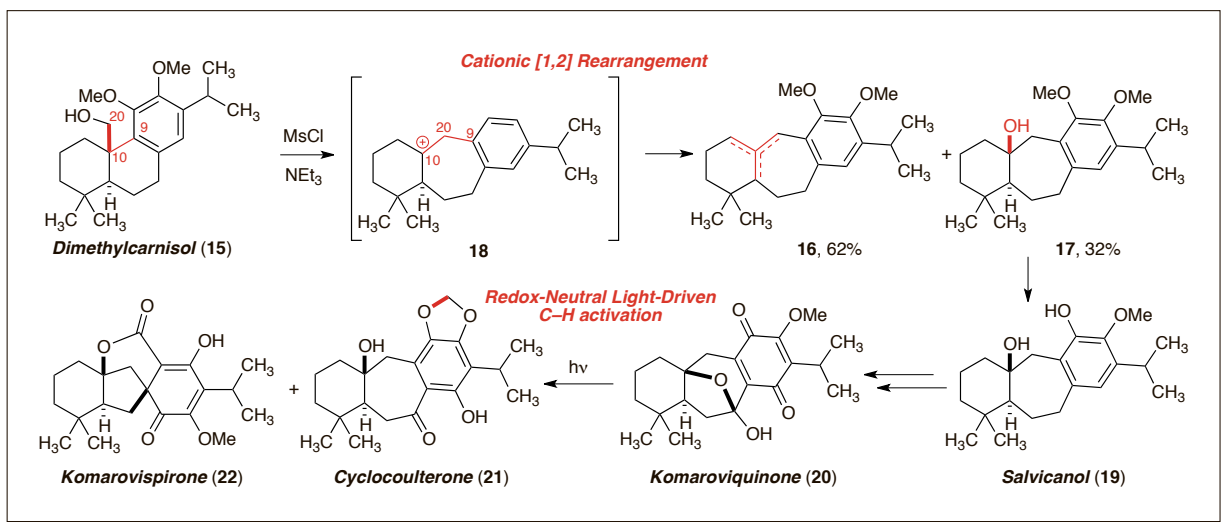

Scheme 4. Collective synthesis to the natural products salvicanol (19) and komaroviquinone (20) using a biosynthetically proposed cationic [1,2]-rearrangement, and redox-neutral light-driven $\mathrm{C}-\mathrm{H}$ activation of $\mathbf{2 0}$ to cyclocoulterone (21) and komarovispirone (22).

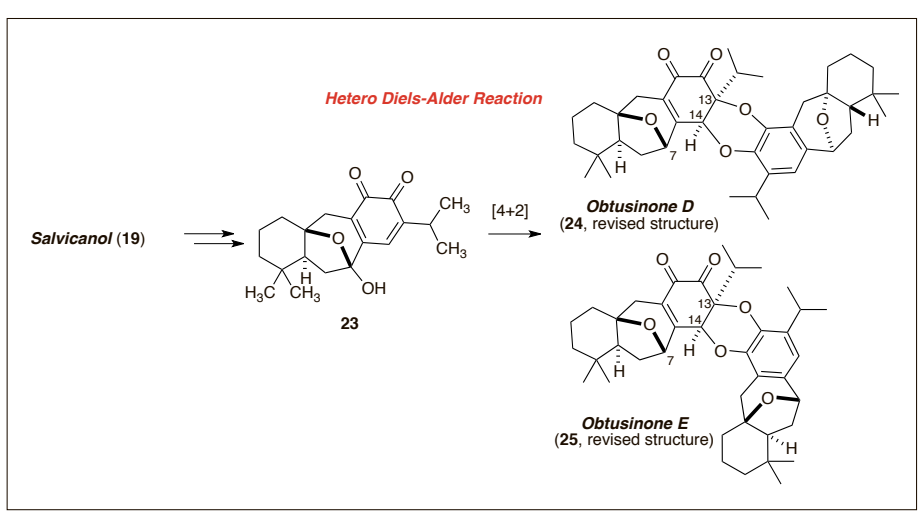

Scheme 5 .

Biomimetic dimerization of $\mathbf{2 3}$ in a hetero Diels-Alder reaction to the natural products obtusinone $D$ (24) and $E(25)$

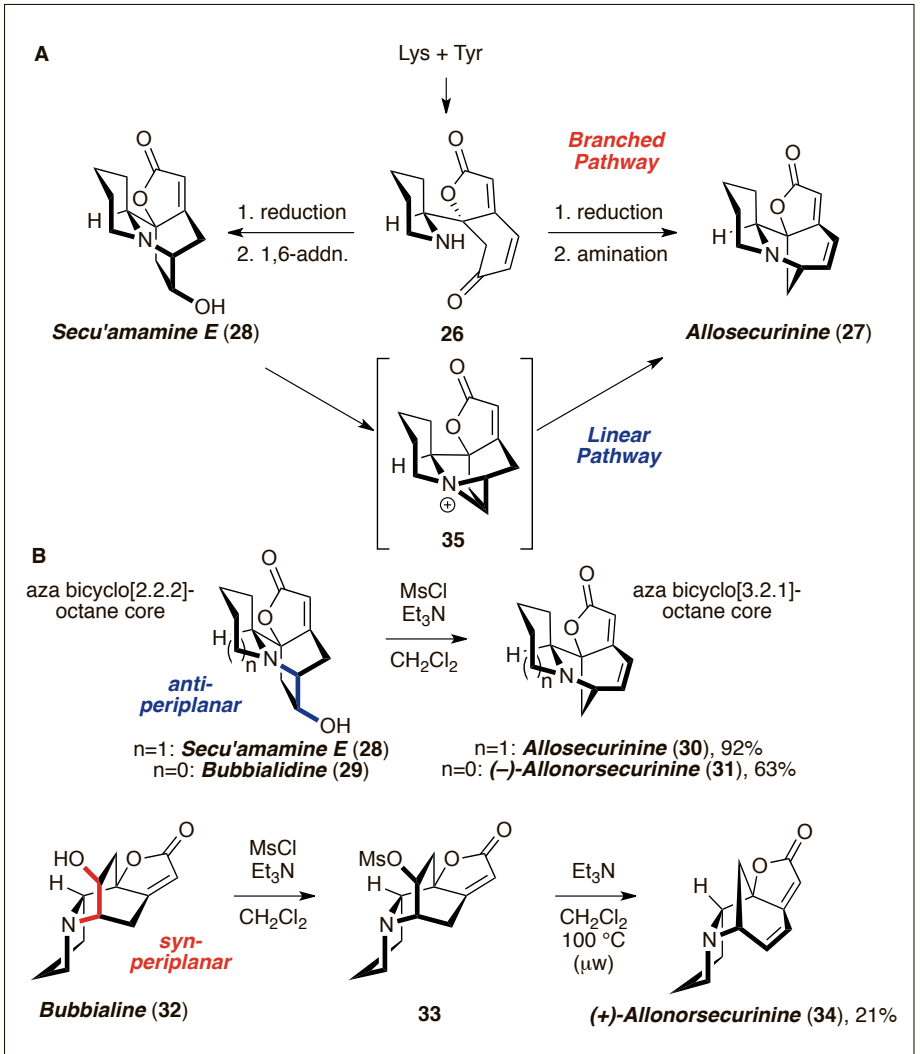

Scheme 6. A) Biogenetic hypothesis to Securinega alkaloids; B) Dehydrative rearrangement of Securinega alkaloids.
Flueggea virosa ${ }^{[21]}$ and displays an interesting cage-like structure as a member of the Securinega alkaloids. Virosaine A was suggested to be the product of an intramo- lecular [1,3]-dipolar cycloaddition, which triggered synthetic efforts by three groups, including ours, towards its preparation. ${ }^{[22]}$ All synthetic efforts involve such a cycload- 


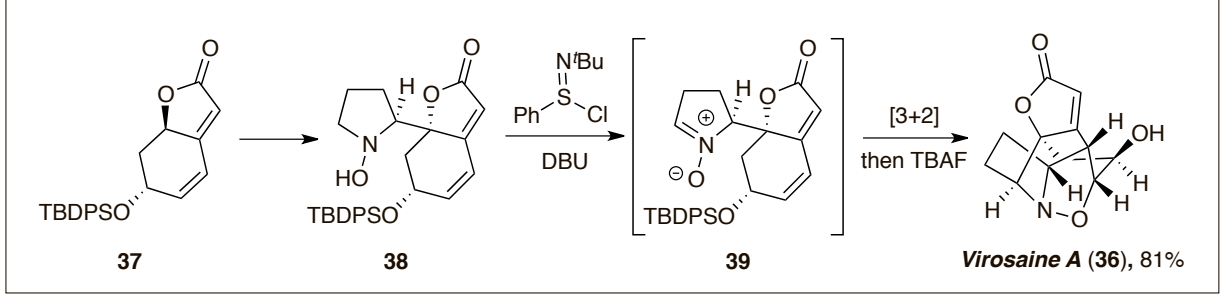

Scheme 7. Total synthesis of virosaine A via a proposed [3+2]-nitrone olefin cycloaddition.

dition at one stage, the reaction which also was shown by computational approaches to be reasonable. Our synthesis started from TBDPS-protected (+)-aquilegiolide 37, which was obtained from commercially available 1,4-dioxaspiro[4.5]decan-8-one in seven steps and $15 \%$ overall yield. A sequence via Mannich reaction, aza-Michael addition and Cope elimination furnished hydroxylamine 38, which was the key intermediate to investigate the biogenetic proposal. Oxidation of this compound by $N$ - $t$-butylbenzenesulfinimidoyl chloride resulted in the completely regioselective formation of the intermediate nitrone 39, and an immediate intramolecular [3+2]nitrone olefin cycloaddition was observed (Scheme 7). Deprotection then yielded virosaine A (36) in good yield, which was found to display identical spectral properties to the natural product. The chemical feasibility of this nitrone olefin cycloaddition suggests the possibility of this process to occur in nature, although this still needs to be further investigated. A recent computational study provided further mechanistic insight. ${ }^{[23]}$

\section{Conclusion}

In this account, we presented an overview of chemical exploratory work into yet underexplored mechanistic possibilities of biosynthetic transformations. Many of these examples suggest that the biosynthetic realm in terms of reactions is not fully mapped out, and that reactions such as benzilic acid rearrangements or [3+2] cycloaddition reactions might be involved in some biosynthetic processes, which remain to be fully characterized in nature.

Received: October 31, 2017

[1] Cited in 'Chemische Zeitreisen', K.-D. Röker, Books on Demand, 2012, ISBN 9783848213580.

[2] RÖMPP Naturstoffe, Georg-Thieme-Verlag, Stuttgart, 1997.

[3] a) 'Biochemical Pathways', Ed. G. Michal, Spektrum Akademischer Verlag, Heidelberg, 1999; b) 'The Organic Chemistry of Biological Pathways', Eds. J. McMurry, T. Begley, Roberts and Company Publishers, Greenwood Village, CO, USA, 2005.

[4] D. Zhang, H. Ge, J.-H. Zou, X. Tao, R. Chen, J. Dai, Org. Lett. 2014, 16, 1410.

[5] R. Liffert, A. Linden, K. Gademann, J. Am. Chem. Soc. 2017, 139, 16096.

[6] G. Majetich, J. M. Shimkus, J. Nat. Prod. 2010, 73, 284.

[7] a) A. Tahara, Chem. Pharm. Bull. 1961, 9, 252; b) J. F. Grove, B. J. Riley, J. Chem. Soc. 1961, 1105 ; c) B. Brückner, D. Blechschmidt, R. D. Recknagel, J. Basic Microbiol. 1991, 31, 243; d) J. MacMillan, D. A. Ward, A. L. Phillips, M. J. Sanchez Beltran, P. Gaskin, T. Lange, P. Hedden, Plant Physiol. 1997, 113, 1369; e) B. Tudzynski, Appl. Microbiol. Biotechnol. 1999, 52, 298; f) J. Anaya, J. J. Fernandez, M. Grande, J. Martianez, P. Torres, Nat. Prod. Commun. 2008, 3, 483; g) L. N. Mander, Nat. Prod. Rep. 2003, 20, 49.

[8] a) C. Kumar Jana, R. Scopelliti, K. Gademann, Chem. Eur. J 2010, 16, 7692; b) C. Kumar Jana, R. Scopelliti, K. Gademann, Synthesis 2010, 13, 2223.

[9] a) A. T. Rowland, P. J. Bennett, T. S. Shoupe, J. Org. Chem. 1968, 33, 2426; b) R. Hanna, G. Maalouf, B. Muckensturm, A. Cherry, Tetrahedron 1973, 29, 2297; c) A. T. Rowland, R. S. Drawbaugh, J. R. Dalton, J. Org. Chem. 1977, 42, 487; d) H. Duddeck, J. Frelek, D. Horvatic, B. Kojicprodic, G. Snatzke, W. J. Szczepek, P. Wagner, J. Phys. Org. Chem. 1990, 3, 404.
[10] C. Thommen, C. Kumar Jana, M. Neuburger, K. Gademann, Org. Lett. 2013, 15, 1390.

[11] a) W. Bauer, M. H. Zhenk, Phytochemistry 1991, 30, 2953; b) E. Ono, M. Nakai, Y. Fukui, N. Tomomori, M. Fukuchi-Mizutami, M. Saito, H. Satake, T. Tanaka, M. Katzuka, T. Umezawa, Y. Tanaka, Proc. Natl. Acad. Sci. USA 2006, 103 10116; c) N. Ikezawa, K. Iwasa, F. Sato, FEBS J. 2007, 274, 1019.

[12] a) C.-I. Chang, S.-C. Chien, S.-M. Lee, Y.-H Kuo, Chem. Pharm. Bull. 2003, 51, 1420; b) C.I. Chang, J.-Y. Chang, C.-C. Kuo, W.-Y. Pan, Y.H. Kuo, Planta Med. 2005, 71, 72 .

[13] C. Thommen, M. Neuburger, K. Gademann, Chem. Eur. J. 2017, 23, 120.

[14] a) M. Yatagai, T. Takahashi, Phytochemistry 1980, 19, 1149; b) A. Kelecom, Tetrahedron 1983, 39, 3603; c) S. Hasegawa, Y. Hirose, M. Yatagai, T. Takahashi, Chem. Lett. 1984, 13, 1837; d) T. Kametani, H. Kondoh, M. Tsubuki, T. Honda, J. Chem. Soc. Trans. 1990, 5.

[15] a) W. H. Watson, Z. Taira, X. A. Dominguez, H. Gonzales, M. Guiterrez, R. Aragon, Tetrahedron Lett. 1976, 17, 2501; b) C. Sánchez, J. Cárdenas, L. Rodríguez-Hahn, T. P. Ramamoorthy, Phytochemistry 1989, 28 , 1681 ; c) A. G. González, L. S. Andrés, J. G. Luis, I. Brito, M. L. Rodríguez, Phytochemistry 1991, 30, 4067; d) B. M. Fraga, C. E. Díaz, A. Guadaño, A. González-Coloma, J. Agric. Food Chem. 2005, 53, 5200; e) E. Simmons, J. R. Yen, R. Sarpong, Org. Lett. 2007, 9, 2705; f) Z.-Y. Ziang, C.-G. Huang, H.-B. Xiong, K. Tian, W.-X- Liu, Q.-F. Hu, H.-B. Wang, G.-Y. Yang, X.-Z. Huang, Tetrahedron Lett. 2013, 54, 3886.

[16] B. Galli, F. Gasparrini, V. Lanzotti, D. Misiti, R Riccio, C. Villani, H. Guan-Fu, M. Zhong-Wu, Y. Wan-Fen, Tetrahedron 1999, 55, 11385.

[17] Y. Aoyagi, Y. Takahashi, Y. Satake, H. Fukaya, K Takeya, R. Aiyama, T. Matsuzaki, S. Hashimoto, T. Shiina, T. Kurihara, Tetrahedron Lett. 2005, 46,7885 .

[18] A.-W. Salae, N. Boonnak, Tetrahedron Lett. 2013, 54, 1356.

[19] R. Wehlauch, K. Gademann, Asian J. Org. Chem. 2017, 6, 1146.

[20] R. Wehlauch, S. M. Grendelmeier, H. MiyatakeOndozabal, A. H. Sandtorv, M. Scherer, K. Gademann, Org. Lett. 2017, 19, 548.

[21] B.-X. Zhao, Y. Wang, D.-M. Zhang, X.-J. Huang, L.-L. Bai, Y. Yan, J.-M. Chen, T.-B. Lu, Y.-T. Wang, Q.-W. Zhang, W.-C. Ye, Org. Lett. 2012, 14, 3096 .

[22] a) J. M. E. Hughes, J. L. Gleason, Angew. Chem. Int. Ed. 2017, 56, 10830; b) H. Wei, C. Qiao, G. Liu, Z. Yang, C.-C. Li, Angew. Chem. Int. Ed. 2013, 52, 620; c) H. Miyatake-Ondozabal, L. M. Bannwart, K. Gademann, Chem. Commun. 2013, 49, 1921.

[23] P. P. Painter, R. P. Pemberton, B. M. Wong, K. C. Ho, D. J. Tantillo, J. Org. Chem. 2014, 79, 432. 